\title{
Diaphragmatic function after intense exercise in congestive heart failure patients
}

\author{
T.J. Kufel, L.A. Pineda, R.G. Junega, R. Hathwar, M.J. Mador
}

\begin{abstract}
Diaphragmatic function after intense exercise in congestive heart failure patients. T.J. Kufel, L.A. Pineda, R.G. Junega, R. Hathwar, M.J. Mador. (C)ERS Journals Ltd 2002

ABSTRACT: Respiratory muscle strength and endurance is reduced in patients with congestive heart failure, making these patients susceptible to diaphragmatic fatigue during exercise.

In order to determine whether or not contractile fatigue of the diaphragm occurs in patients with congestive heart failure following intense exercise, twitch transdiaphragmatic pressures (twitch $\left.P_{t d i}\right)$ were measured during unpotentiated and potentiated cervical magnetic stimulation (CMS) of the phrenic nerves before and at intervals after cycle endurance exercise.

Ten patients aged $65.7 \pm 6.0$ yrs (mean \pm SD) with an ejection fraction of $31.2 \pm 9.8 \%$ performed a constant-load symptom-limited exercise test at $60 \%$ of their peak work capacity. Twitch $P$ tdi at baseline were $15.9 \pm 6.3 \mathrm{cmH}_{2} \mathrm{O}$ (unpotentiated CMS) and $28.8 \pm$ $10.7 \mathrm{cmH}_{2} \mathrm{O}$ (potentiated $\mathrm{CMS}$ ) and at $10 \mathrm{~min}$ postexercise were $16.4 \pm 4.7 \mathrm{cmH}_{2} \mathrm{O}$ (unpotentiated CMS) and $27.6 \pm 10.1 \mathbf{c m H}_{2} \mathrm{O}$ (potentiated CMS). One patient demonstrated a sustained fall in twitch $P_{t d i}$ of $\geqslant 15 \%$, considered potentially indicative of diaphragmatic fatigue.

Contractile diaphragmatic fatigue is uncommon in untrained patients with congestive heart failure following high-intensity constant-workload cycle exercise. Therefore, diaphragmatic fatigue is an unlikely cause of exercise-limitation during activities of daily living in heart failure patients.

Eur Respir J 2002; 20: 1399-1405.
\end{abstract}

Division of Pulmonary and Critical Care Medicine, Veterans Administration Western New York Healthcare System, Dept of Medicine, State University of New York at Buffalo School of Medicine and Biomedical Sciences, Buffalo, NY, USA.

Correspondence: T.J. Kufel, Division of Pulmonary and Critical Care Medicine (111S), VA Western New York Healthcare System, 3495 Bailey Avenue, Buffalo, New York 14215, USA.

Fax: 17168628632

E-mail: thomas.kufel@med.va.gov

Keywords: Congestive heart failure, diaphragm, exercise, fatigue

Received: February 252002

Accepted after revision: July 92002

This study was supported by a Grantin-Aid from the American Heart Association, New York State Affiliate, Inc., Syracuse, NY, USA.
Exercise intolerance due to dyspnoea and fatigue is a frequent and disabling symptom in patients with congestive heart failure (CHF). Some investigators believe that inspiratory muscle fatigue might be an important mediator of dyspnoea during exercise in $\mathrm{CHF}$ [1]. Conclusive data showing that intense exercise causes diaphragmatic fatigue in patients with $\mathrm{CHF}$ are not available.

The limb muscles of patients with heart failure undergo changes that predispose them to reduced endurance and contractile fatigue [2]. Similar changes might occur in the inspiratory skeletal muscles. Studies have found respiratory muscle weakness [3] and reduced respiratory muscle endurance [4] in patients with $\mathrm{CHF}$. In addition, patients with heart failure show an increased ventilatory response to exercise [5], further exacerbating the imbalance between inspiratory muscle capacity and load. Therefore, it is reasonable to hypothesise that diaphragmatic fatigue may occur in patients with $\mathrm{CHF}$ when stressed by exercise.

The limited studies investigating respiratory muscle fatigue in patients with $\mathrm{CHF}$ after exercise are inconclusive. MANCINI et al. [1] failed to demonstrate evidence of diaphragmatic fatigue after exercise using transcutaneous electrical stimulation of the phrenic nerves. However, the negative results may be explained partially by the fact that they failed to account for twitch potentiation, obtaining twitch measurements immediately after exercise [6]. Furthermore, the work of LEVINE and HENSON [7] suggests that an incremental exercise protocol, as used by MANCINI et al. [1], is of insufficient intensity and duration to result in diaphragmatic fatigue. Recently, Hughes et al. [8] demonstrated a slowing of the inspiratory muscle relaxation rate (MRR) in $\mathrm{CHF}$ patients after exercise, implying that inspiratory muscle loading is excessive during exercise and the inspiratory muscles are in a potentially fatiguing pattern of contraction. However, this does not confirm that overt muscle fatigue is present since slowing of the MRR precedes overt muscle fatigue. Furthermore, TIKUNOv et al. [9] found an increased proportion of type I (slow-twitch fatigue-resistant) fibres and an increase in oxidative enzyme activity in the diaphragm of patients with $\mathrm{CHF}$, suggesting that the diaphragm of heart failure patients may be more fatigue-resistant. These findings and the methodological problems described above prohibit definitive conclusions and warrant further investigation using new techniques and different methodology. Magnetic stimulation of the phrenic nerves is an accepted 
alternative to electrical stimulation and is a nonvolitional, simple and reproducible technique of assessing inspiratory muscle function that reduces the difficulties encountered with electrical stimulation [10].

The purpose of the present study was to determine whether or not contractile fatigue of the diaphragm occurs in patients with moderately severe heart failure following intense exercise. Accordingly, transdiaphragmatic twitch pressure (twitch $P$ tdi) was measured during supramaximal cervical magnetic stimulation (CMS) before and after high-intensity endurance cycle exercise to the limits of tolerance in a group of patients with $\mathrm{CHF}$.

\section{Methods}

\section{Subjects}

Ten male patients with $\mathrm{CHF}$ aged $65.7 \pm 6.0$ yrs (mean \pm SD), of height $1.77 \pm 0.09 \mathrm{~m}$ and weight $89.7 \pm 15.7 \mathrm{~kg}$, volunteered for the present study. The diagnosis of CHF was based on a history of dyspnoea on exertion, fluid retention, fatigue and a left ventricular ejection fraction of $\leqslant 35 \%$. All patients were clinically stable at the time of the study and free from overt pulmonary, musculoskeletal or neurological disease that could affect exercise performance. Patients with peripheral vascular disease, a pacemaker, uncontrolled hypertension, or abnormal electrolyte or haemoglobin levels were excluded. The aetiology of the $\mathrm{CHF}$ was ischaemic in nine of the patients and idiopathic in the remaining patient. The medications taken included digoxin $(n=2)$, diuretics $(n=9)$, angiotensin-converting enzyme inhibitor $(n=10)$, nitrates $(n=6)$ and $\beta$-blockers $(n=2)$. Four patients were in New York Heart Association functional Class II and six in Class III. The appropriate institutional review boards approved the study and informed consent was obtained from all subjects.

\section{Study design}

The resting left ventricular ejection fraction was obtained by gated cardiac blood pool study. Pulmonary function was measured using standard techniques according to American Thoracic Society recommendations [11]. Maximal inspiratory pressure $(P \mathrm{I}, \max )$ was measured as previously described [12]. Cardiac and pulmonary function measurements are shown in table 1.

A maximal symptom-limited incremental cycle exercise test was performed to determine the peak work capacity ( $W$ peak) of each subject as previously described [12]. Several days after the incremental exercise test, subjects performed constant-workload exercise at $60 \%$ of $W$ peak until they were no longer able to maintain a pedalling frequency of $>50$ revolutions per minute despite verbal encouragement. All exercise tests, calculations of peak and mean inspiratory pressure swings, and measurement of arterialised lactate levels were performed as described previously [12]. Immediately after exercise
Table 1.-Cardiac and pulmonary function measurements

\begin{tabular}{|c|c|c|}
\hline & $\begin{array}{l}\text { Absolute } \\
\text { value }\end{array}$ & $\begin{array}{l}\text { Percentage of } \\
\text { predicted value }^{\#}\end{array}$ \\
\hline LVEF \% & $31.2 \pm 9.8$ & \\
\hline FEV1 L & $2.70 \pm 0.48$ & $77.3 \pm 7.8$ \\
\hline FVC L & $3.54 \pm 0.55$ & $78.6 \pm 6.8$ \\
\hline $\mathrm{FEV}_{1} / \mathrm{FVC} \%$ & $75.6 \pm 4.0$ & \\
\hline TLC L & $6.11 \pm 0.92$ & $89.0 \pm 14.5$ \\
\hline RV L & $2.46 \pm 0.56$ & $103.1 \pm 29.2$ \\
\hline$D \mathrm{~L}, \mathrm{CO} \mathrm{mL} \cdot \mathrm{min}^{-1} \cdot \mathrm{mmHg}^{-1}$ & $22.27 \pm 8.0$ & $81.0 \pm 25.0$ \\
\hline$P \mathrm{I}, \max \mathrm{cmH}_{2} \mathrm{O}$ & $94 \pm 21$ & $87.1 \pm 18.0$ \\
\hline $\mathrm{MVV} \mathrm{L} \cdot \mathrm{min}^{-1}$ & $109.1 \pm 21.0$ & $82.2 \pm 11.4$ \\
\hline
\end{tabular}

Data are presented as mean \pm SD. LVEF: left ventricular ejection fraction; FEV1: forced expiratory volume in one second; FVC: forced vital capacity; TLC: total lung capacity; RV: residual volume; $D$ L,CO: diffusing capacity of the lung for carbon monoxide; PI,max: maximal inspiratory pressure; MVV: maximum voluntary ventilation. \#. from [13-16].

was discontinued, patients were asked to choose the symptom that they felt was most responsible for stopping exercise.

CMS of the phrenic nerve was achieved using a commercial magnetic stimulator (Magstim 200; Magstim Co. Ltd., Whitland, UK) and a 90-mm coil $(\mathrm{n}=10)$ [9]. The technical details of this procedure have been described previously [12]. Recent work suggests that the potentiated twitch may be a more sensitive index of fatigue $[17,18]$. Therefore, $P$ tdi twitch force (twitch $P$ tdi) was measured using CMS 5 s after a 5-s maximal Mueller manoeuvre against an occluded airway in eight patients.

Diaphragmatic compound muscle action potentials (M-wave) were recorded with surface electrodes. The technical details of this procedure have been described previously [12]. Magnetic stimulation often results in a large shock artefact that obscures the initial portion of the M-wave. However, with repositioning of the surface electrodes and ground before initial measurements, satisfactory $\mathrm{M}$-waves were obtained before and after exercise in five subjects.

Twitch Ptdi was defined as the peak amplitude above the immediately preceding Ptdi baseline. Approximately eight twitches by CMS and five potentiated twitches were obtained before and 10, 30 and $60 \mathrm{~min}$ after exercise. In order to prevent twitch potentiation, the unpotentiated twitches were obtained prior to measuring the potentiated twitch. Individual twitches were rejected from analysis using previously defined criteria [19].

\section{Statistical analysis}

Changes in variables over time were analysed by repeated-measures analysis of variance. If the result of the analysis of variance was significant, measurements after exercise were compared to baseline using a paired t-test with Bonferroni correction. For each individual patient, a fall in twitch $P$ tdi after exercise of $\geqslant 15 \%$ at 10 and 30 min was considered potentially indicative of diaphragmatic fatigue. Before the study 
Table 2. - Cardiopulmonary parameters during endurance exercise

\begin{tabular}{|c|c|c|c|}
\hline & Resting & Mid-exercise & End-exercise \\
\hline$V^{\prime} \mathrm{O}_{2} \mathrm{~L} \cdot \mathrm{min}^{-1}$ & $0.34 \pm 0.04$ & $1.36 \pm 0.30$ & $\begin{array}{c}1.39 \pm 0.21 \\
(62.2 \pm 13.4)\end{array}$ \\
\hline$f_{\mathrm{C}}$ beats $\cdot \mathrm{min}^{-1}$ & $76.1 \pm 15.0$ & $128.4 \pm 12.0$ & $\begin{array}{c}131.4 \pm 16.4 \\
(85.2+11.2)\end{array}$ \\
\hline$V^{\prime} \mathrm{E} \mathrm{L} \cdot \min ^{-1}$ & $12.3 \pm 1.74$ & $41.9 \pm 7.66$ & $50.9 \pm 9.1^{\uparrow}$ \\
\hline$V \mathrm{~T} \mathrm{~L}$ & $0.68 \pm 0.16$ & $1.47 \pm 0.46$ & $1.49 \pm 0.39$ \\
\hline$f_{\mathrm{R}}$ breaths $\cdot \mathrm{min}^{-1}$ & $18.6 \pm 3.4$ & $31.3 \pm 11.2$ & $33.4 \pm 11.9$ \\
\hline$t \mathrm{I} \mathrm{s}$ & $1.32 \pm 0.24$ & $0.99 \pm 0.36$ & $0.93 \pm 0.32$ \\
\hline$t \mathrm{I} /$ tot & $0.40 \pm 0.24$ & $0.46 \pm 0.03$ & $0.47 \pm 0.03$ \\
\hline$P$ tdi $\mathrm{cmH}_{2} \mathrm{O}$ & $9.57 \pm 3.31$ & $17.78 \pm 4.93$ & $17.76 \pm 4.04$ \\
\hline $\mathrm{T} t \mathrm{di}$ & $0.021 \pm 0.007$ & $0.048 \pm 0.011$ & $0.049 \pm 0.014$ \\
\hline Ttoes & $0.016 \pm 0.007$ & $0.064 \pm 0.030$ & $0.066 \pm 0.034$ \\
\hline $\mathrm{PTP}_{\text {di }} \mathrm{cmH}_{2} \mathrm{O} \cdot \mathrm{s}^{-1} \cdot \mathrm{min}^{-1}$ & $127.6 \pm 50.0$ & $300.8 \pm 77.0$ & $301.5 \pm 64.2$ \\
\hline PTPoes $\mathrm{cmH}_{2} \mathrm{O} \cdot \mathrm{s}^{-1} \cdot \mathrm{min}^{-1}$ & $86.7 \pm 34.1$ & $325.8 \pm 86.0$ & $331.2 \pm 94.7$ \\
\hline Lactate $\mathrm{mEq} \cdot \mathrm{L}^{-1}$ & $1.6 \pm 0.6$ & & $5.1 \pm 1.4$ \\
\hline
\end{tabular}

Data are presented as mean $\pm \mathrm{SD}$ with the percentage of the predicted value in parentheses. $V^{\prime} \mathrm{O}_{2}$ : oxygen consumption; $f \mathrm{C}$ : cardiac frequency; $V^{\prime} \mathrm{E}$ : minute ventilation; $V \mathrm{~T}$ : tidal volume; $f \mathrm{R}$ : respiratory frequency; $t \mathrm{I}$ : inspiratory time; $t \mathrm{I} / t$ tot: duration of total breathing cycle; $P$ tdi: transdiaphragmatic pressure; T $t$ di: tension/time index of the diaphragm; T toes: tension/time index of the oesophagus; PTPdi: pressure/time product of the diaphragm; PTPoes: pressure/time product of the oesophagus. ${ }^{\#}: \mathrm{p}=0.002$ versus resting; ${ }^{\bullet} \mathrm{p}=0.03$ versus mid-exercise.

was performed, a power analysis was conducted assuming a normal distribution, an $\alpha$ level of 0.05 and a power of 0.95 . Using a within-subject betweentrial coefficient of variation of $8 \%$, it was found that a sample size of seven would be required to detect a $15 \%$ decrease in mean value (one-tailed). Data are expressed as mean \pm SD.

\section{Results}

\section{Cardiopulmonary parameters during exercise}

The peak oxygen consumption $\left(V^{\prime} \mathrm{O}_{2}\right)$ measured during incremental exercise was $1.29 \pm 0.31 \mathrm{~L} \cdot \mathrm{min}^{-1}$ or $14.4 \pm 2.3 \mathrm{~mL} \cdot \mathrm{kg}^{-1} \cdot \mathrm{min}^{-1}$, which was $59 \pm 18 \%$ of the predicted maximum. The $W$ peak was $95 \pm 17 \mathrm{~W}$ $(64 \pm 19 \%$ of the predicted maximum). During incremental exercise, peak ventilation was $53 \pm 14 \mathrm{~L} \cdot \mathrm{min}^{-1}$, which represented $49 \pm 15 \%$ of the 12 -s maximum voluntary ventilation (MVV) and the peak cardiac frequency was $134 \pm 22$ beats $\cdot \mathrm{min}^{-1}(87 \pm 1 \%$ of the predicted maximum).

Cardiopulmonary parameters measured during the constant-load endurance test are shown in table 2.

The patients exercised for a mean of $10.1 \pm 3.4 \mathrm{~min}$ during the constant-load test at a workload of $57 \pm 11 \mathrm{~W}(60 \pm 2 \%$ of $W$ peak $)$. The peak $V^{\prime} \mathrm{O}_{2}$ during constant-load exercise was $1.39 \pm 0.21 \mathrm{~L} \cdot \mathrm{min}^{-1}$, which was $111 \pm 16 \%$ of the peak $V^{\prime} \mathrm{O}_{2}$ obtained during the incremental exercise test. The peak ventilation attained during constant-load exercise was $51 \pm 9 \mathrm{~L} \cdot \mathrm{min}^{-1}$, representing $48 \pm 14 \%$ of the 12 -s MVV. Peak cardiac frequency was $131 \pm 16$ beats $\cdot \mathrm{min}^{-1}(85 \pm 11 \%$ of the predicted maximum). At the end of exercise, four patients cited "shortness of breath" as the cause of exercise termination and six stopped exercise because of "leg fatigue".

\section{Diaphragm twitch force}

Twitch Ptdi (unpotentiated and potentiated) was not significantly different from baseline at any time after exercise (fig. 1). Gastric and oesophageal twitch pressures (table 3 ) were also not significantly different

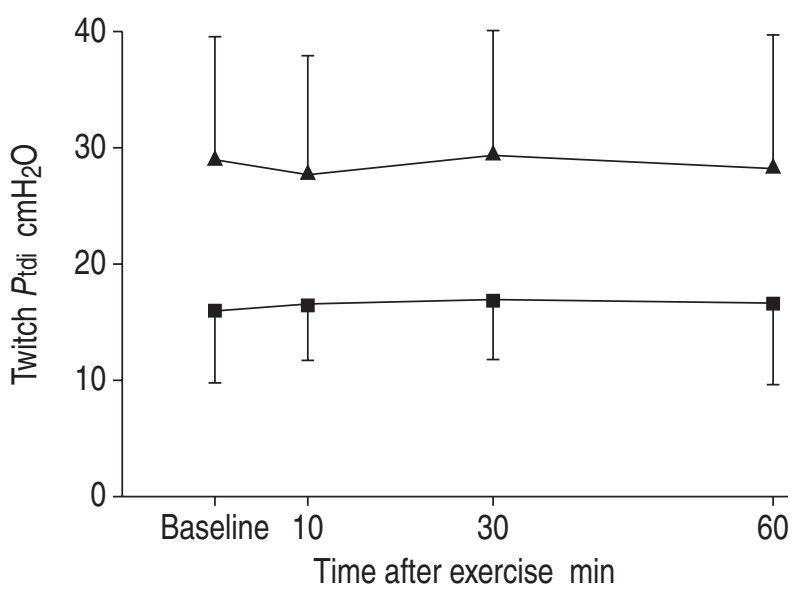

Fig. 1. - Unpotentiated $(\boldsymbol{\square} ; \mathrm{n}=10)$ and potentiated $(\boldsymbol{\Delta} ; \mathrm{n}=8)$ twitch transdiaphragmatic pressures (twitch $P_{\text {tdi) }}$ before and 10, 30 and $60 \mathrm{~min}$ after exercise. Twitch $P$ tdi was not significantly different from baseline at any time after exercise. Data are presented as mean \pm SD.

Table 3. - Unpotentiated twitch pressures

\begin{tabular}{lrrrr}
\hline & Baseline & \multicolumn{3}{c}{ Post-exercise } \\
\cline { 3 - 5 } & & $10 \mathrm{~min}$ & $30 \mathrm{~min}$ & $60 \mathrm{~min}$ \\
\hline$P_{\text {oes } \mathrm{cmH}_{2} \mathrm{O}}$ & $11.6 \pm 4.3$ & $12.2 \pm 4.1$ & $12.4 \pm 4.1$ & \begin{tabular}{r}
$12.7 \pm 4.8$ \\
$P_{\text {ga } \mathrm{CmH}_{2} \mathrm{O}}$ \\
\cline { 2 - 4 }
\end{tabular} \\
\hline
\end{tabular}

Data are presented as mean \pm SD. Poes: oesophageal pressure; $P$ ga: gastric pressure. 

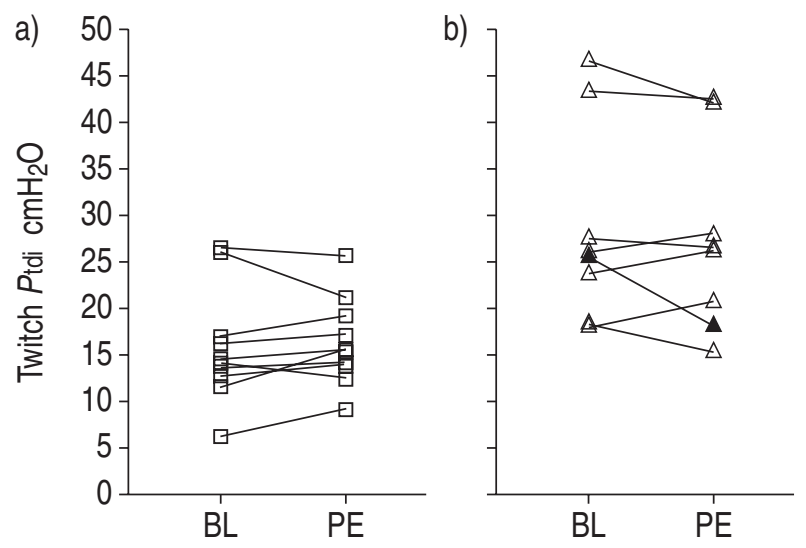

Fig. 2. - a) Unpotentiated and b) potentiated twitch transdiaphragmatic pressure (twitch $P$ tdi) before (baseline (BL)) and $10 \mathrm{~min}$ after high-intensity cycling at $60 \%$ of maximal work capacity to volitional exhaustion (post-exercise (PE)) in each subject. Patients who displayed $a \geqslant 15 \%$ reduction in twitch $P$ tdi after exercise that persisted for $30 \mathrm{~min}$ were considered to have demonstrated diaphragmatic fatigue ( $\mathbf{\Delta})$; patients who did not meet these criteria were considered nonfatiguers $(\% \square, \% \triangle)$.

from baseline at any time after exercise. One patient demonstrated a sustained fall in potentiated twitch $P$ tdi after exercise (fig. 2).

A diaphragmatic electromyogram was recorded for all subjects. Diaphragmatic M-wave amplitude was not significantly different from baseline at any time after exercise in the five subjects in whom it could be accurately measured at all times points. In the five subjects for whom M-waves could be obtained, there was no significant change in twitch $P$ tdi at any time after exercise compared with baseline. PI,max was $94 \pm 21 \mathrm{cmH}_{2} \mathrm{O}$ at baseline and $93 \pm 25 \mathrm{cmH}_{2} \mathrm{O}$ immediately after exercise $(\mathrm{p}=\mathrm{NS})$.

\section{Breathing pattern during exercise}

Mean inspiratory $P$ tdi, oesophageal pressure $\left(P_{\text {oes }}\right)$ and minute ventilation $\left(V^{\prime} \mathrm{E}\right)$ are shown in figure 3. Mean inspiratory $P$ tdi reached peak values early in exercise. $V^{\prime} E$ increased substantially early in exercise and more gradually as exercise progressed until a plateau was reached near the end of exercise. The mean inspiratory $P$ oes reached a plateau near midexercise. The pressure/time products and tension/time indices are shown in table 2.

\section{Lactate measurements}

Lactate concentration increased from $1.6 \pm 0.6 \mathrm{mEq} \cdot \mathrm{L}^{-1}$ at baseline to $5.1 \pm 1.4 \mathrm{mEq} \cdot \mathrm{L}^{-1}$ immediately after exercise $(\mathrm{p}=0.001)$ and had recovered to $2.9 \pm 0.7 \mathrm{mEq} \cdot \mathrm{L}^{-1}$ at 30 min after exercise $(\mathrm{p}=\mathrm{NS})$.

\section{Discussion}

The major conclusion of the present study is that contractile fatigue of the diaphragm is uncommon in untrained patients with moderately severe CHF.

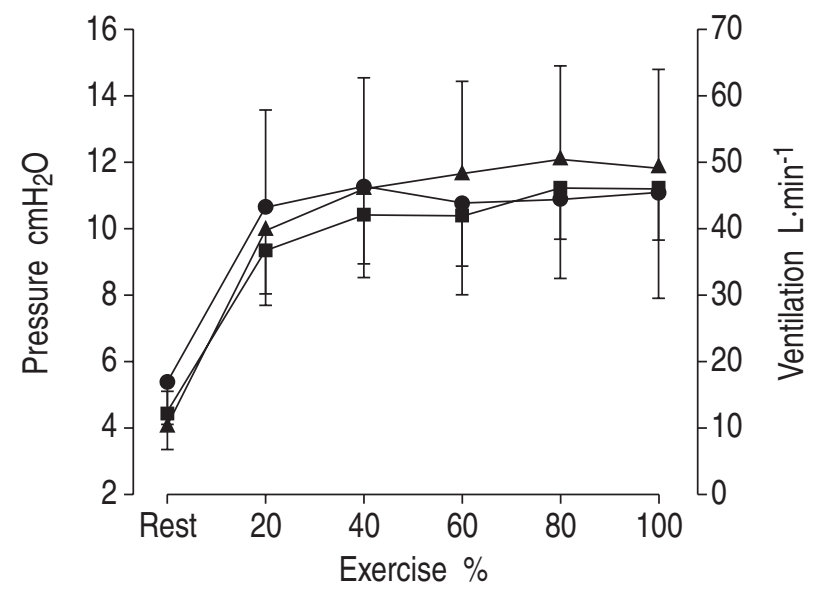

Fig. 3. - Mean inspiratory transdiaphragmatic ( $P$ tdi; $\bigcirc)$ and oesophageal $\left(P_{\text {oess }} \boldsymbol{\Delta}\right)$ pressures and minute ventilation $\left(V^{\prime} \mathrm{E} ; \boldsymbol{\square}\right)$ at rest and during exercise. After $20 \%$ of the exercise time, $P$ tdi, $P_{\text {oes }}$ and $V^{\prime} \mathrm{E}$ reached 97,83 and $81 \%$ of their maximal value, respectively.

\section{Critique of methods}

Unpotentiated CMS was used to detect diaphragmatic fatigue in a group of patients with CHF. The authors' laboratory has considerable experience with CMS and transcutaneous electrical stimulation in normal subjects and patients [6,12,19-22]. CMS was utilised in the present study because this method is well tolerated and technically easier to perform than transcutaneous electrical stimulation. Furthermore, congruent changes in twitch Ptdi were demonstrated with CMS and transcutaneous electrical stimulation in patients with chronic obstructive pulmonary disease (COPD) before and after high-intensity exercise [12]. Unlike electrical stimulation, CMS can potentially detect both ribcage and diaphragmatic fatigue [23], and fatigue of either muscle group would be clinically relevant. Thus, it was felt that CMS was ideal for the proposed experiments.

Patients were exercised at $60 \%$ of their peak workload based on prior studies performed in the authors' laboratory. Normal subjects demonstrated evidence of diaphragmatic fatigue after voluntary hyperpnoea at a $V^{\prime} \mathrm{E}$ of $60 \% \mathrm{MVV}$ sustained for $\sim 8$ min [21]. Furthermore, diaphragmatic fatigue was found in normal volunteers after endurance exercise in which subjects exercised for a mean of $8 \mathrm{~min}$ at a $V^{\prime}$ E that was $50 \%$ of their MVV [22]. JoHnson et al. [24] suggested that high-intensity exercise should be sustained for $\geqslant 10 \mathrm{~min}$ in order to produce significant diaphragmatic fatigue. Therefore, it was felt that a workload of $60 \% W$ peak would be tolerated by patients and probably result in an exercise $V^{\prime} \mathrm{E}$ of sufficient intensity $(\sim 50 \% \mathrm{MVV})$ and duration (8-10 $\mathrm{min})$ to cause diaphragmatic fatigue. The subjects exercised for $10 \mathrm{~min}$ at a $V^{\prime} \mathrm{E}$ of $48 \%$ of 12 -s MVV. Thus they attained levels of ventilation and exercise duration similar to those previously shown to result in diaphragmatic fatigue.

Twitch potentiation [6] and lung volume changes [25] are important variables that can influence twitch 
$P$ tdi. A vigorous voluntary contraction can increase twitch Ptdi amplitude (twitch potentiation). It has previously been shown that diaphragmatic twitch potentiation decays exponentially with the greatest change occurring within the first $2 \mathrm{~min}$ and was minimal ( $<4 \%$ above baseline) 8 min after a vigorous muscle contraction [6]. Therefore, the first set of postexercise twitch measurements were obtained $10 \mathrm{~min}$ after exercise and subsequent sets of unpotentiated twitches were obtained $\geqslant 15$ min after any potentiation manoeuvre. End-expiratory lung volume is known to increase during exercise in patients with CHF [26]. It rapidly returns to baseline after stopping exercise in patients with COPD [27]. Patients with CHF should behave similarly.

Some may argue that significant recovery could occur during the 10-min period after stopping exercise that was allowed in the present study for the effects of twitch potentiation to resolve. However, reductions in twitch force after a fatiguing task reflect lowfrequency fatigue that is known to recover very slowly. LAGHI et al. [17] demonstrated a reduction in twitch $P$ tdi after resistive loading that did not return to baseline levels when measured $\sim 20 \mathrm{~h}$ after task failure. Therefore, complete recovery from diaphragmatic fatigue within $10 \mathrm{~min}$ of terminating exercise, would not be expected.

\section{Diaphragmatic fatigue and exercise}

No change was found in twitch $P$ tdi obtained by two different methods after high-intensity cycle exercise in a group of patients with moderately severe $\mathrm{CHF}$ (fig. 1). None of the patients demonstrated a sustained fall of $15 \%$ in unpotentiated twitch Ptdi. LAGHI et al. [17] suggested that the potentiated twitch might be a more sensitive method for evaluating small changes in diaphragmatic contractility. In order to investigate the possibility that the unpotentiated twitch missed some patients with a small amount of diaphragmatic fatigue, potentiated twitch was measured in eight patients. One patient demonstrated a persistent fall in potentiated twitch $P$ tdi suggestive of fatigue. The changes in potentiated twitch $P$ tdi for that patient were greater than but consistent with those observed with the unpotentiated method. The within-subject between-trial coefficient of variation in the authors' laboratory for CMS is $6.1 \pm 1 \%$ [19]. A persistent $15 \%$ reduction (which is greater than twice the mean variability) in twitch $P$ tdi was chosen as being potentially indicative of diaphragmatic fatigue. A $10 \%$ cut-off would have identified two patients by the unpotentiated and potentiated methods. Interestingly, the two subjects that met the less rigid criteria identified dyspnoea as the cause of terminating exercise. It is possible that diaphragmatic fatigue is more common in those patients who identify dyspnoea as the single factor limiting exercise performance. However, as reported by HAMILTON et al. [28], isolated dyspnoea as the cause of premature termination of exercise is found in $<15 \%$ of cardiac patients. Further study in this select group may be warranted; however, the aim of the present study was to determine whether or not diaphragmatic fatigue occurs in a representative group of heart failure patients. There were no apparent differences between the subject who might have developed diaphragmatic fatigue after exercise and the remainder of the group in terms of left ventricular function, medication, pulmonary function, baseline exercise data or work performed during exercise.

Recently, data on 10 healthy elderly subjects aged 68.3 yrs were reported [20]. These subjects exercised at $\sim 70 \%$ of their predetermined peak workload for nearly $18 \mathrm{~min}$ and generated an exercise ventilation of $50 \%$ MVV. Similar to the heart failure patients presented in the current report, no change was seen in twitch $P$ tdi from baseline at any time after exercise using CMS, bilateral anterolateral magnetic stimulation or the potentiated technique. At end-exercise, the pressure/time products of the oesophagus and diaphragm for the healthy elderly were $316 \pm 29$ and $311 \pm 28 \mathrm{cmH}_{2} \mathrm{O} \cdot \mathrm{s}^{-1} \cdot \mathrm{min}^{-1}$ (mean $\left.\pm \mathrm{SEM}\right)$, respectively. The end-exercise tension/time indices of the oesophagus and diaphragm were $0.057 \pm 0.005$ and $0.044 \pm 0.004$, respectively. None of these values were significantly different from those obtained in the present heart failure patients. Comparisons of the study in the healthy elderly to the current study in heart failure patients is legitimate despite the fact that the healthy elderly subjects exercised slightly more intensely ( $70 \%$ of peak workload). Despite exercising at a greater workload for a longer duration, the healthy elderly did not attain greater ventilation than the heart failure patients (mean \pm SEM $58.8 \pm 4.7$ versus mean \pm SD $50.9 \pm 9.1 \mathrm{~L} \cdot \mathrm{min}^{-1}$, respectively; $\left.\mathrm{p}=\mathrm{NS}\right)$ and did not demonstrate diaphragmatic fatigue despite exercising for a longer period of time. Since the healthy elderly normal subjects did not demonstrate diaphragmatic fatigue at a workload greater than that used in the present heart failure study, they would not be expected to demonstrate diaphragmatic fatigue if exercised at a lesser workload.

The present authors and others have observed diaphragmatic fatigue after endurance exercise in young healthy adults [22, 24]. Why might healthy young people develop diaphragmatic fatigue after exercise while older patients with CHF do not? It is felt that exercise-induced diaphragmatic fatigue requires a high level of sustained diaphragmatic work and an unspecified exercise-dependent factor [29]. The present subjects sustained exercise for a sufficient duration to result in fatigue. However, was the diaphragmatic work of high enough intensity to result in diaphragmatic fatigue? The pressure/time product and tension/ time index were measured as estimates of inspiratory muscle work during exercise. In the present authors' laboratory, the peak pressure/time product of the oesophagus for young sedentary subjects who demonstrated diaphragmatic fatigue after exercise was significantly greater than that achieved by the patients with $\mathrm{CHF}\left(585 \pm 52 \mathrm{cmH} \mathrm{O}_{2} \cdot \mathrm{s}^{-1} \cdot \mathrm{min}^{-1}(\right.$ mean $\pm \mathrm{SEM})$, $\mathrm{p}<0.001$ ) [22]. However, maximal inspiratory muscle strength was lower in the elderly CHF patients than in subjects of the previous study of younger healthy subjects [22]. Thus, the tension/time index of the oesophagus in the heart failure patients was not 
significantly different from that observed in the young sedentary subjects $(0.066 \pm 0.01$ versus $0.083 \pm 0.009$, $\mathrm{p}=\mathrm{NS}$ ). This suggests that the heart failure patients performed similar amounts of inspiratory muscle work relative to their capacity, and, despite exercising intensely for sufficient duration, the majority of patients did not display evidence of diaphragmatic fatigue after exercise.

Could the present subjects have attained higher levels of inspiratory muscle work? The heart failure patients were highly motivated and exercise data indicate that they terminated exercise at their physiological limits. At the end of endurance exercise, peak $V^{\prime} \mathrm{O}_{2}$ was $111 \pm 16 \%$ of the peak $V^{\prime} \mathrm{O}_{2}$ obtained during the incremental maximal exercise test, and peak cardiac frequency was $85 \pm 11 \%$ of the predicted maximum. The peak lactate levels generated by the heart failure patients were significantly lower than those observed in the healthy elderly (mean \pm SD $5.1 \pm 1.4$ versus mean \pm SEM $6.8 \pm 0.6 \mathrm{mEq} \cdot \mathrm{L}^{-1} ; \mathrm{p}=0.03$ ) [20], but was not significantly different from that observed in a group of patients with COPD (mean \pm SEM $4.8 \pm 0.5 \mathrm{mEq} \cdot \mathrm{L}^{-1} ; \mathrm{p}=\mathrm{NS}$ ) [30]. Thus, the present subjects appear to have exercised maximally. The rationale for getting patients to exercise at $60 \%$ of their incremental $W$ peak is reviewed above. A greater workload could have resulted in greater inspiratory muscle work, although peak exercise ventilation was similar during the endurance and maximal incremental exercise tests, but it is unlikely that patients with heart failure would be capable of sustaining higher workloads for very long. It is possible that the present subjects could not attain higher levels of inspiratory muscle work because they were forced to stop exercise because of peripheral leg muscle fatigue. It has previously been shown that quadriceps muscle fatigue occurs following endurance exercise in elderly patients [20] and in patients with COPD [30]. This possibility deserves further investigation in heart failure patients. The present data are consistent with the increased proportion of type I (slow-twitch fatigue-resistant) fibres and increase in oxidative enzyme activity in the diaphragm of patients with $\mathrm{CHF}$ demonstrated by TIKUnOv et al. [9]. Perhaps the increased work of breathing observed in patients with CHF trains the respiratory muscles as postulated for patients with COPD. These adaptations make the diaphragm more fatigue-resistant and offer an attractive explanation for the present findings.

It is well known that ageing and chronic disease result in a reduction in physical activity, deconditioning and a reduction in maximal work capacity. Exercise training in patients with CHF is increasing in popularity and has been shown to increase exercise capacity, reduce mortality and improve quality of life [31]. Whether a trained heart failure patient can perform enough work during exercise to develop diaphragmatic fatigue remains to be determined.

\section{Conclusion}

Contractile diaphragmatic fatigue is uncommon in untrained patients with moderately severe heart failure after a bout of constant workload exercise of greater intensity than is commonly expected during the activities of daily living for such patients. Thus, diaphragmatic fatigue is unlikely to be an important cause of exertional symptoms and exercise limitation in the majority of untrained patients with heart failure.

\section{References}

1. Mancini DM, Henson D, LaManca J, Levine S. Respiratory muscle function and dyspnea in patients with chronic congestive heart failure. Circulation 1992; 86: 909-918.

2. Mancini DM, Walter G, Reichek N, et al. Contribution of skeletal muscle atrophy to exercise intolerance and altered muscle metabolism in heart failure. Circulation 1992; 85: 1364-1373.

3. Hammond MD, Bauer KA, Sharp JT, Rocha D. Respiratory muscle strength in congestive heart failure. Chest 1990; 98: 1091-1094.

4. Mancini DM, Henson D, LaManca J, Levine S. Evidence of reduced respiratory muscle endurance in patients with heart failure. J Am Coll Cardiol 1994; 24 : 972-981.

5. Sullivan MJ, Higginbotham MB, Cobb FR. Increased exercise ventilation in patients with chronic heart failure: intact ventilatory control despite haemodynamic and pulmonary abnormalities. Circulation 1988; 77: 552-557.

6. Mador MJ, Magalang UJ, Kufel TJ. Twitch potentiation following voluntary diaphragmatic contraction. Am J Respir Crit Care Med 1994; 149: 739-743.

7. Levine S, Henson D. Low-frequency diaphragmatic fatigue in spontaneously breathing humans. $J$ Appl Physiol 1988; 64: 672-680.

8. Hughes PD, Hart N, Hamnegard $\mathrm{CH}$, et al. Inspiratory muscle relaxation rate slows during exhaustive treadmill walking in patients with chronic heart failure. Am J Respir Crit Care Med 2000; 163: 14001403.

9. Tikunov B, Levine S, Mancini D. Chronic congestive heart failure elicits adaptations of endurance exercise in diaphragmatic muscle. Circulation 1997; 95: 910916.

10. Similowski T, Fleury B, Launois S, Cathala HP, Bouche P, Derenne JP. Cervical magnetic stimulation: a new painless method for bilateral phrenic nerve stimulation in conscious humans. J Appl Physiol 1989; 67: 1311-1318.

11. American Thoracic Society. Standardization of spirometry: 1994 update. Am J Respir Crit Care Med 1995; 152: $1107-1136$.

12. Mador MJ, Kufel TJ, Pineda LA, Sharma GK. Diaphragmatic fatigue and high-intensity exercise in patients with chronic obstructive pulmonary disease. Am J Respir Crit Care Med 2000; 161: 118-123.

13. Crapo RO, Morris AH, Gardner RM. Reference spirometric values using techniques and equipment that meet ATS recommendations. Am Rev Respir Dis 1981; 123: 659-664.

14. Crapo RO, Morris AH. Standardized single breath normal values for carbon monoxide diffusing capacity. Am Rev Respir Dis 1981; 123: 185-189.

15. Crapo RO, Morris AH, Clayton PD, Nixon CR. Lung 
volumes in healthy nonsmoking adults. Bull Eur Physiopathol Respir 1982; 18: 419-425.

16. McElvaney G, Blackie S, Morrison NJ, Wilcox PG, Fairbarn MS, Pardy RL. Maximal static respiratory pressures in the normal elderly. Am Rev Respir Dis 1989; 139: 277-281.

17. Laghi F, Topeli A, Tobin MJ. Does resistive loading decrease diaphragmatic contractility before task failure? J Appl Physiol 1998; 85: 1103-1112.

18. Kufel TJ, Pineda LA, Mador MJ. Comparison of potentiated and unpotentiated twitches as an index of muscle fatigue. Muscle Nerve 2002; 25: 438444.

19. Mador MJ, Rodis A, Magalang UJ, Ameen K. Comparison of cervical magnetic and transcutaneous phrenic nerve stimulation before and after threshold loading. Am J Respir Crit Care Med 1996; 154: 448453.

20. Mador MJ, Kufel TJ, Pineda LA. Quadriceps and diaphragmatic function following exhaustive cycle exercise in the healthy elderly. Am J Respir Crit Care Med 2000; 162: 1760-1766.

21. Mador MJ, Rodis A, Diaz J. Diaphragmatic fatigue following voluntary hyperpnea. Am J Respir Crit Care Med 1996; 154: 63-67.

22. Mador MJ, Magalang UJ, Rodis A, Kufel TJ. Diaphragmatic fatigue after exercise in healthy human subjects. Am Rev Respir Dis 1993; 148: 15711575.

23. Similowski T, Straus C, Attali V, Duguet A, Derenne JP. Cervical magnetic stimulation as a method to discriminate between diaphragm and ribcage muscle fatigue. J Appl Physiol 1998; 84: 1692-1700.

24. Johnson BD, Babcock MA, Suman OE, Dempsey JA. Exercise-induced diaphragmatic fatigue in healthy humans. J Physiol 1993; 460: 385-405.

25. Smith JF, Bellemare F. Effect of lung volumes on in vivo contraction characteristics of human diaphragm. J Appl Physiol 1987; 62: 1893-1900.

26. O'Donnell DE, D'Arsigny C, Raj S, Abdollah H, Webb KA. Ventilatory assistance improves exercise endurance in stable congestive heart failure. $\mathrm{Am}$ J Respir Crit Care Med 1999; 160: 1804-1811.

27. Polkey MI, Kyroussis D, Keilty SEJ, et al. Exhaustive treadmill exercise does not reduce twitch transdiaphragmatic pressure in patients with COPD. Am J Respir Crit Care Med 1995; 152: 959-964.

28. Hamilton AL, Killian KJ, Summers E, Jones NL. Symptom intensity and subjective limitation to exercise in patients with cardiorespiratory disorders. Chest 1996; 110: 1255-1263.

29. Babcock MA, Pegelow DF, McClaran, Suman OE, Dempsey JA. Contribution of diaphragmatic power output to exercise-induced diaphragm fatigue. $J$ Appl Physiol 1995; 78: 1710-1719.

30. Mador MJ, Kufel TJ, Pineda L. Quadriceps fatigue after cycle exercise in patients with chronic obstructive pulmonary disease. Am J Respir Crit Care Med 2000; 161: 447-453.

31. Belardinelli R, Georgiou D, Ciani G, Purcaro A. Randomized, controlled trial of long-term moderate exercise training in chronic heart failure. Circulation 1999; 99: 1173-1182. 